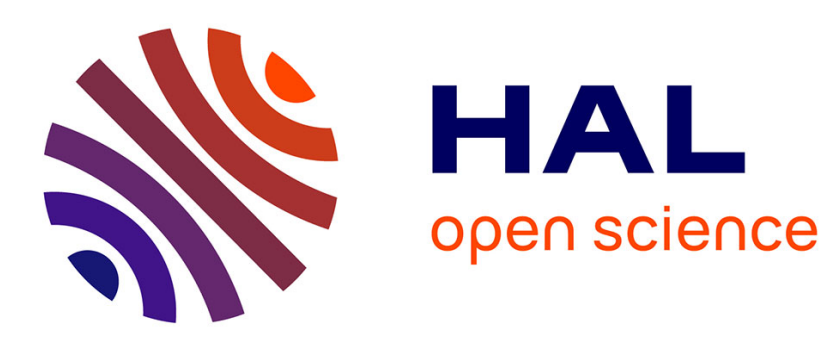

\title{
Quantification of ignition time uncertainty based on the classical ignition theory and Fourier analysis
}

Aymeric Lamorlette

\section{To cite this version:}

Aymeric Lamorlette. Quantification of ignition time uncertainty based on the classical ignition theory and Fourier analysis. Comptes Rendus Mécanique, 2014, 342 (8), pp.459 - 465. 10.1016/j.crme.2014.06.002 . hal-01096403

\section{HAL Id: hal-01096403 https://hal.science/hal-01096403}

Submitted on 17 Dec 2014

HAL is a multi-disciplinary open access archive for the deposit and dissemination of scientific research documents, whether they are published or not. The documents may come from teaching and research institutions in France or abroad, or from public or private research centers.
L'archive ouverte pluridisciplinaire HAL, est destinée au dépôt et à la diffusion de documents scientifiques de niveau recherche, publiés ou non, émanant des établissements d'enseignement et de recherche français ou étrangers, des laboratoires publics ou privés. 


\title{
Quantification of ignition time uncertainty based on the classical ignition theory and Fourier analysis
}

\author{
Aymeric Lamorlette ${ }^{\mathrm{a}}$ \\ a Aix-Marseille Université, CNRS, Centrale Marseille \\ M2P2 UMR 7340, 13451 Marseille, France Tel (33) 491113811 ; Fax (33) 491118502 \\ Received *****; accepted after revision +++++ \\ Presented by
}

\begin{abstract}
This study aims at modeling the effect of incoming heat flux fluctuations, on solid material ignition. In order to propose a general methodology based on the classical ignition theory that can be applied to any kind of solid target, kernels accounting for the target temperature response regarding an incoming heat flux are considered for thermally thick and thin solids with low or high thermal inertia. A Fourier decomposition of the incoming heat flux is then used to calculate the target response to harmonic heat fluxes. Finally, effects of harmonic fluctuations on ignition are discussed based on the previous analytical results, allowing to discriminate situations where ignition time is expected to be rather predictable from situations where ignition time is expected to be less predictable thanks to an uncertainty quantification of the ignition time. To cite this article: Aymeric Lamorlette, C. R. Mecanique 333 (2005).
\end{abstract}

Résumé

Quantification de l'incertitude du temps d'ignition fondée sur la théorie classique de l'ignition et l'analyse de Fourier Cette étude a pour but la modélisation des effets des fluctuations du flux de chaleur impactant un matériau solide sur l'ignition de ce dernier. Afin de proposer une méthodologie générale, fondée sur la théorie classique de l'ignition, qui pourra être appliquée à n'importe quel type de cible, des noyaux rendant compte de la réponse en température à une sollicitation thermique sont considérés pour des solides thermiquement épais et fins, et pour de basses et hautes inerties thermiques. Une décomposition en séries de Fourier de la sollicitation est alors utilisée pour calculer la réponse de la cible aux flux harmoniques. Finalement, les effets de ces fluctuations sont discutés à partir des résultats analytiques précédent, permettant de discriminer des situations où le temps d'ignition devrait être plutôt prédictible de situations où il risque d'être moins prédictible, et ce grâce à une quantification de l'incertitude du temps d'ignition. Pour citer cet article: Aymeric Lamorlette, C. R. Mecanique 333 (2005).

Key words: Heat transfer ; Piloted ignition; Ignition uncertainty

Mots-clés : Transfert thermiques; Ignition pilotée; Incertitude de l'ignition 


\section{Introduction}

In the frame of fire safety applications, estimation of flaming ignition time of solid material is a major issue. A first approximation, often called the classical ignition theory, consists in considering ignition as two separated mechanisms: Heat and pyrolysis of the solid followed by chemical reactions in the gas phase. If the pyrolysis gas flow is low with normal oxygen concentration and suggesting that ignition occurs when the solid surface temperature reaches the pyrolysis temperature, the ignition time corresponds to the time needed by the solid to heat until it begin its pyrolysis. Indeed, chemical time and mixing time are typically much smaller than pyrolysis time for piloted flaming ignition. These assumptions allow to model ignition as a temperature rise process in the solid material as suggested by [1]. Ignition is thus modeled as a one-dimensional heat conduction problem as proposed by [2] for thermally thick surfaces and as a zerodimension heat transfer problem for thermally thin particles as suggested in [3]. In order to mimic more realistic fire scenarios, an improvement of this theory is proposed in [4], where the radiant heat flux is suggested to be linearly time depending, as suggested by [5] to take into account the time-varying heat flux on a stationary target exposed to a spreading fire front. Using this approach, the global trend of the incoming radiant heat flux can be taken into account. However, turbulent motions are common in the fire front as explained by [6] and often generate periodic or quasi-periodic flame behavior as demonstrated by [7] and [8], thus periodic or quasi-periodic fluctuations of the radiant heat flux can occur that are not taken into account in the previously described modeling. These fluctuations could be responsible for ignition or fire propagation unpredictabilities since they are not controlled in practical applications: Recent experimental results on fire propagation by [9] demonstrate the existence of quasi-periodic fluctuations of the heat flux involving flaming contact on the solid particles composing a fuel layer which seems to be of great matter in particle ignition. Moreover, the study of [10] demonstrates the effect of wind fluctuations on fire propagation, involving processes similar to those suggested in [9].

Therefore, this study aims at modeling the effect of heat flux harmonic variations on different solid target of interest, to mimic the effect of the previously described periodic or quasi-periodic processes and investigate ignition uncertainty. The latter is defined as the harmonic flux effect on the temperature rise. It can nevertheless be noticed that if chemical and mixing time were to be considered, uncertainties due to chemistry and mixing should be added to the uncertainty due to the temperature rise, particularly when addressing ignition of the smaller targets, according to [11]. This aspect is however not investigated in this study. The suggested target could be PMMA and wood slabs, insulating foams, excelsior or pine needles, which can be classified as thermally thick or thin, with low or high thermal inertia, according to the classification suggested in [11]. Hence ignition is modeled for these solid categories. Solutions are discussed for practical fire safety applications, thus use of "practical" in this article will refer to material thermophysical properties of PMMA, wood and insulating foams, with ignition time ranging from a few seconds to a few hundred seconds. The limit (regarding the particle size) between thermally thin and thermally thick material is set according to [12], where a radiative Biot number, depending on the incoming radiant heat flux, is considered. Indeed, a classical Biot number cannot fully account for the thermal behavior transition since heating is here due to radiative heat transfer.

In order to illustrate the incoming heat flux harmonic variation effect, an example considering the ignition under heat fluxes composed of a constant and a harmonic part is presented. Nevertheless, the methodology allows to extend the study to heat fluxes composed of any kind of slow time-varying variations part adding any harmonic part.

Email address: aymeric.lamorlette@univ-amu.fr (Aymeric Lamorlette). 


\section{Mathematical formulation: The classical ignition theory}

This section recalls the work of $[1,2,3,4,11]$, using a particular formalism which provides a simple expression for the target temperature response to a Fourier decomposition of the incoming heat flux, and suggesting a slight difference for low thermal inertia solids. Indeed, the study of [11] considers series expansion around $t \rightarrow \infty$ whereas this study considers a higher series expansion (in comparison with the high thermal inertia case) around $t \rightarrow 0$.

For thermally thick targets, a one-dimensional semi-infinite inert solid material is considered with one side exposed to an incoming heat flux $\Phi(t)$. The heat conduction equation is solved for the solid target, introducing $\theta(x, t)=T(x, t)-T_{0}$ where $T(x, t)$ is the solid temperature and $T_{0}$ the initial temperature of both the solid and its surrounding air. $\lambda, \rho, C p$ and $h$ represent respectively the solid heat conductivity, its density, its specific heat and a total heat transfer coefficient.

For high thermal inertia solids, the associated surface heat loss can be neglected as shown in $[4,11]$ whereas it is taken into account for low thermal inertia solids. Hence, kernel $K$ is provided by the classical solution suggested in $[2,11]$ for high thermal inertia solids. Since the study focuses on the surface temperature evolution, the kernel $K$ is calculated at $x=0$, leading to:

$$
K(0, t)=\frac{2 \sqrt{t}}{\sqrt{\pi \lambda \rho C p}} .
$$

Now, considering an arbitrary function $\Phi(\tau)$ as series of steps and using the heat diffusion equation linearity, the response $\theta(0, t)$ can be expressed as a sum of response with time offsets for an arbitrary kernel $K_{0}$ :

$$
\theta(0, t)=\int_{0}^{t} \frac{d \Phi}{d \tau} K_{0}(0, t-\tau) d \tau .
$$

This result is similar to the solution suggested by [13] for the heat diffusion equation with $K_{0}(0, t)=$ $K(0, t)$.

For low thermal inertia solids, a kernel $K_{H}(0, t)$ that take into account the surface heat losses through a total heat transfer coefficient $h$ is provided, according to [2]:

$$
K_{H}(0, t)=\frac{1}{h}\left[1-\exp \left(\frac{h^{2}}{\lambda \rho C p} t\right) \operatorname{erfc}\left(\frac{h}{\sqrt{\lambda \rho C p}} \sqrt{t}\right)\right] .
$$

The practical use of this kernel is however limited due to its mathematical form. Nevertheless it can be simplified assuming that even for material with low thermal inertia, the characteristic time $\tau_{K_{H}}=$ $\lambda \rho C p / h^{2}$ of the kernel $K_{H}(0, t)$ is always larger than the ignition time, allowing series expansion of the kernel around $t \rightarrow 0$. The latter is then re-written as $K_{H}(0, t)=K(0, t)+K_{h}(0, t)$ with

$$
K_{h}(0, t) \approx-\frac{h t}{\lambda \rho C p}+\frac{4}{3} \frac{h^{2} t^{3 / 2}}{\sqrt{\pi}(\lambda \rho C p)^{3 / 2}} .
$$

Application of this simplified kernel to a linear time-dependent heat flux does not strictly allow recovering the series expansion result of [4] since the series expansion has been made before calculating the convolution. The solution suggested here is nevertheless more accurate regarding the exact solution than the solution proposed in [4] which has been experimentally validated, thus validating the simplified kernel. Indeed, in most practical cases, the ignition time is lower than the kernel characteristic time and the series expansion provides an efficient approximation. 
In order to assert this assumption, the characteristic time $\tau_{K_{H}}$ is calculated for typical material as wood, polymer and insulating foam. Thermophysical properties of these material are extracted from $[14,15,16,17,18]$ and are listed in table 1 . In order to estimate the total heat transfer coefficient, different approaches can be suggested. For instance, in [19], this coefficient stands for radiant re-emission only and its value is maximized, providing $h=22 \mathrm{~W} \cdot \mathrm{m}^{-2} \cdot \mathrm{K}^{-1}$. Linearized values of this coefficient provide $h$ in the range $18-20 \mathrm{~W} \cdot \mathrm{m}^{-2} \cdot \mathrm{K}^{-1}$ regarding the reference temperature (ignition or mean temperature between ambient and ignition temperature). The convective heat transfer coefficient can also be added to this coefficient, as suggested in [3], however natural convection on a flat surface is often expected to be negligible regarding radiant re-emission. This assumption is questionable for small targets according to [11]; however, in the case of thermally thick material, it seems acceptable. For thermally thin materials, the total heat transfer coefficient should then be a bit higher. Finally, in [20], this coefficient is set at $10 \mathrm{~W} \cdot \mathrm{m}^{-2} \cdot \mathrm{K}^{-1}$. Thus, a value in the range $10-20 \mathrm{~W} \cdot \mathrm{m}^{-2} \cdot \mathrm{K}^{-1}$ is used in this study, which seems an acceptable range. Therefore, considering wood, $\tau_{K_{H}} \in[270 ; 4000] \mathrm{s}$; For polymer, $\tau_{K_{H}} \in[260 ; 10000] \mathrm{s}$ while $\tau_{K_{H}} \in[2 ; 150] \mathrm{s}$ for insulating foams. It must be noticed that [14] suggests slightly lower values in the case of very low thermal inertia. These ranges are summarized in table 1 , showing (for wood and polymer) the relevancy of series expansion for ignition times ranging from a few seconds to a few hundred seconds. For insulating foam, the efficiency of series expansion observed in [4] in case of ignition time up to 400 s however suggests that the efficient characteristic time $\tau_{K_{H}}$ for foam is much greater than table 1 values. Hence, practical dimensionless ignition time $t^{*}$ (defined as $t^{*}=t_{i g} / \tau_{K_{H}}$ ) for thermally thick solids will be considered lower or equal to one.

For thermally thin solid targets, such as solid particles composing a forest fuel layer, the solution suggested in [3] is used, providing the thermally thin kernel $k(t)$ :

$$
k(t)=\frac{1}{h}\left[1-\exp \left(-\frac{h \sigma}{\rho C p} t\right)\right] .
$$

where $\sigma$ is the specific area of the solid particles. The thermally thin kernel characteristic time is thus $\tau_{k}=\rho C p / h \sigma$. Since the ratio $\tau_{k} / \tau_{K_{H}}=h / \lambda \sigma$ for a given material stands for its convective Biot number, it seems acceptable for the characteristic time $\tau_{k}$ to be considered small in comparison with $\tau_{K_{H}}$.

Thanks to the expression of the convective Biot number, the latter can be estimated for typical forest fuel layer particle, considering $\sigma$ in the range $600-12000 \mathrm{~m}^{-1}$ using values from $[18,21,22]$. It provides $\tau_{k} / \tau_{K_{H}} \in[0.005 ; 0.555]$ for woody fuel particles. However, the thermally thin limit provided by [12] suggests that some of these particles can behave as thermally thick (for radiative Biot number $B i>$ $0.1)$, which corresponds to $\sigma<2640 \mathrm{~m}^{-1}$ for a $10 \mathrm{~kW} \cdot \mathrm{m}^{-2}$ radiant heat flux $\left(10 \mathrm{~kW} \cdot \mathrm{m}^{-2}\right.$ seems to be an acceptable approximation for the heat flux lower limit, according to critical heat fluxes measured in [19]). Hence, the specific area will be considered to range approximately from $3000 \mathrm{~m}^{-1}$ to $12000 \mathrm{~m}^{-1}$ for particles behaving as thermally thin. Thus, the kernel characteristic time $\tau_{k}$ is in the range $1.35-20 \mathrm{~s}$ for the thinner woody fuel particles and in the range $30-444$ s for the thicker woody fuel particles that still behave as thermally thin.

\section{Temperature response to radiant heat fluxes viewed as Fourier series}

The following assumption is now suggested: Effects of radiative heating variations and convective transfer variations can both be represented by apparent incoming heat flux variations. However, to mimic convective heat transfer variations, the apparent incoming heat flux variation magnitude increases as the radiative Biot number decreases, since the thermally thinner particles are the most sensitive to convective heat transfer modifications. Consequently, effects of flame unsteadiness on the radiant heat flux, practical 
uncontrolled variations of heat loss (convective and radiative) and periodic flaming contact (responsible for both incoming heat flux enhancement and heat loss decrease) could be modeled using periodic incoming heat flux variations. This is why the temperature response to a Fourier decomposed heat flux is investigated, providing thanks to Eq.(2), using the heat conduction equation linearity, for an arbitrary kernel $K_{0}$ and a radiant heat flux $\Phi(t)=\Phi_{0}+\sum\left(a_{n} \cos (\omega t)+b_{n} \sin (\omega t)\right)$ :

$$
\theta(t)=\Phi_{0} K_{0}\left(t_{i g}\right)+\omega\left(\sum_{n} I_{c}-\sum_{n} I_{s}\right)
$$

where $\omega=2 \pi n / t_{i g}$,

$$
I_{c n}=b_{n} \int_{t=0}^{t_{i g}} K_{0}\left(t_{i g}-\tau\right) \cos (\omega \tau) d \tau,
$$

and

$$
I_{s n}=a_{n} \int_{t=0}^{t_{i g}} K_{0}\left(t_{i g}-\tau\right) \sin (\omega \tau) d \tau .
$$

Integrals $I_{c} n$ and $I_{s} n$ are solved analytically for the different kernels suggested in this study yet expressions are not provided here for clarity.

In order to account for the different periodic and quasi-periodic heat flux fluctuations involved in realistic ignition situations, pulsation range of buoyant diffusion flames and pool fires are taken as a reference, using for instance results of [23], based on the pioneer work of [24]. Hence, considering equivalent fire diameters ranging from $10^{-2} \mathrm{~m}$ to $5 \mathrm{~m}$ to account for pine needle litter fires up to crown fires, the reference frequencies are expected to be in the range $0.84-16.8 \mathrm{~Hz}$. It corresponds to period in the range $0.06-1.33 \mathrm{~s}$. This range provides a first insight on these frequencies, however higher and lower frequencies should also be considered since other physical phenomenon such as wind gusts, wind/fire front interactions and wind/vegetation interactions could be responsible for a larger frequency range. For instance the study of [10] suggests heat flux variations due to wind gusts, with frequencies in the range $0.0006-0.1 \mathrm{~Hz}$.

\subsection{A criteria to estimate ignition time uncertainty}

The solution $\theta(t)$ is now studied for a radiant heat flux $\Phi(t)=\Phi_{0}+b_{n} \sin (\omega t)$. In order to investigate the effect of the harmonic part and thus ignition time uncertainty, the following expression $f$ is firstly suggested, accounting for the ratio of the temperature rise due to the harmonic part of the radiant heat flux and the temperature rise due to the constant part:

$$
f\left(K_{0}, n\right)=\frac{\omega I_{c n}}{\Phi_{0} K_{0}\left(t_{i g}\right)}
$$

An harmonic dephasing, which is obviously a parameter that is not controlled in a practical ignition case, should also be taken into account. This is why $f$ possible variation range $\Delta f=2|f|$ will be considered to account for ignition time uncertainty. This function is calculated for the different kernels and then studied regarding the harmonic mode $n$, the perturbation relative magnitude $\phi=b_{n} / \Phi_{0}($ with $0<\phi<1)$ and the dimensionless time to ignition $t^{*}=t_{i g} / \tau_{K_{0}}$. As suggested earlier, for thermally thick solids, $\phi$ is mostly accounting for radiant heat flux variations. Since experimental radiant heat fluxes from fire fronts in [25] exhibits only small magnitude temporal variations, $\phi$ is practically expected to be small. On the contrary, 
for thermally thin solids, $\phi$ can also account for heat loss variations which suggests that $\phi$ can increase almost up to 1 when mimicking flame contact on thermally thin particles.

\subsection{Thermally thick target}

In the case of thermally thick target with high thermal inertia, function $f$ is depending only on $n$ and $\phi$ :

$$
f(K, n)=-\frac{1}{2} \phi \frac{S_{\text {Fresnel }}(2 \sqrt{n})}{\sqrt{n}},
$$

where $S_{\text {Fresnel }}$ is the sinusoidal Fresnel integral. For $n \geq 1$, the global trend exhibits a relatively slow yet always decreasing rate regarding $n$ as shown on figure 1 (the curve $t^{*}=0$ corresponds to the high thermal inertia case).

For thermally thick target with low thermal inertia, function $f$ is expressed the following way:

$$
\begin{aligned}
& f\left(K_{H}, n\right)=f\left(K+K_{h}, n\right)=f(K, n)+f\left(K_{h}, n\right), \\
& f\left(K_{h}, n\right)=\frac{1}{2} \phi \frac{t^{*}}{n \pi}-\frac{1}{4} \phi \frac{t^{*} C_{\text {Fresnel }}(2 \sqrt{n})}{n^{3 / 2} \pi},
\end{aligned}
$$

where $C_{\text {Fresnel }}$ is the cosinusoidal Fresnel integral. As previously mentioned, $t^{*}$ is practically expected to be lower or equal to one. Consequently, the first term in $f\left(K_{h}, n\right)$ is always lowering the effect of the term $f(K, n)$ and $f\left(K_{H}, n\right)$ global trend is practically monotonic as shown on figure 1 , where $\Delta f\left(K_{H}, n\right)$ is plotted for different values of $t^{*}$ in the range $t^{*} \in[0 ; 1]$. Effects of the apparent incoming heat flux harmonic part on the ignition are lowered by surface losses which are damping the system response.

This last remark allows the physical interpretation of figure 1 to be done regardless of the thermal inertia. Hence, according to Eq.(10), frequencies that could be responsible for large ignition time uncertainties are independent of the kernel characteristic time. They rather depend on the ignition time. For instance, in the case of high thermal inertia, setting $n>7$ leads to $\Delta f / \phi<0.2$, which means that the potential effect of any harmonic mode $n>7$ on the temperature rise leading to ignition is lower than $20 \%$ of the harmonic perturbation relative magnitude. Setting a $50 \%$ perturbation relative magnitude, if this perturbation oscillates more than seven times before theoretical ignition (i.e. ignition if no perturbation occurs), the solid surface temperature rise error due to harmonic perturbations at theoretical ignition time is lower than $10 \%$ of the temperature rise needed to achieve ignition, what can be considered as acceptable for fire safety application. Relevant frequencies are even lower for low thermal inertia: For instance, when $t^{*}=0.5, \Delta f / \phi<0.2$ for $n>5$.

Considering the previous example with a $50 \%$ perturbation relative magnitude, radiation variation due to flame puffing could then be neglected, even for the larger flame fronts considered in this study, as long as $t_{i g} \geq 10 \mathrm{~s}$. It can be neglected for even smaller ignition time in the case of low thermal inertia materials. For lower frequency phenomenon such as wind gusts, uncertainty can be estimated comparing the considered physical phenomenon period with the ignition time and using Eq.(10), Eq.(11) and Eq.(12).

\subsection{Thermally thin target}

For thermally thin target, function $f$ is expressed the following way:

$$
f(k, n)=-\phi \frac{2 \pi n t^{*}}{4 \pi^{2} n^{2}+t^{* 2}}
$$




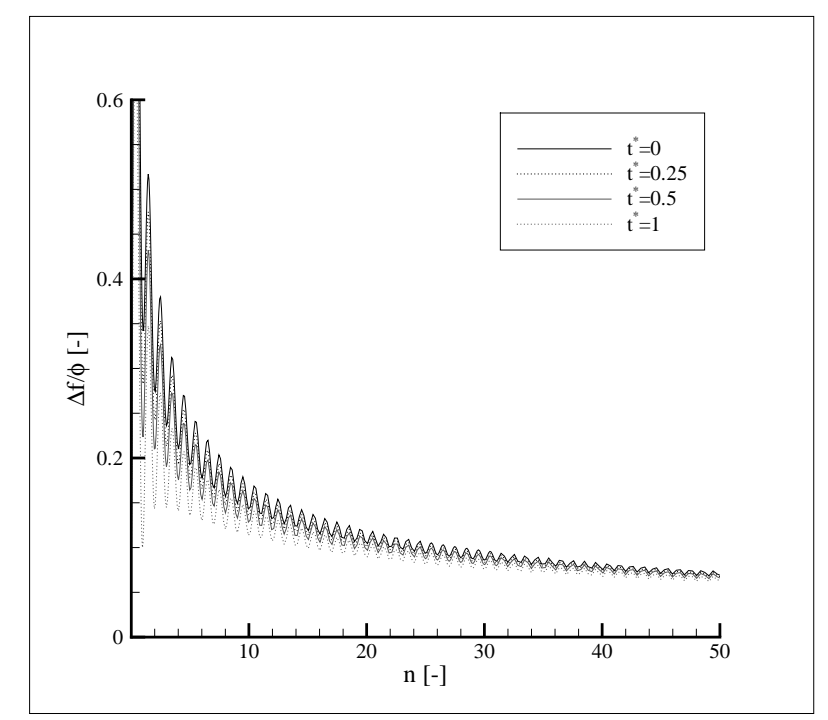

Figure 1. $\Delta f\left(K_{H}, n\right) / \phi$ for $t^{*}=0, t^{*}=0.25, t^{*}=0.5$ and $t^{*}=1$

This relation shows that a non-monotonic behavior of $f$ can occur for $n \geq 1$. Indeed, the kernel and the heat flux solicitation can resonate since $d f(k, n) / d n=0$ when $n_{\text {res }}=t^{*} / 2 \pi$, which corresponds to $T_{\text {res }}=2 \pi \tau_{k}$ where $T_{\text {res }}$ is the resonance period. Hence $\Delta f_{\text {max }}=\phi$ when $n=n_{\text {res }}$, showing clearly that some harmonic variations of the heat flux (with period in the range 8.5-250s for thin forest fuel particles) can greatly modify the ignition time of thermally thin targets. A plot of $f(k, n) / \phi$ is provided on figure 2 for $t^{*}=10, t^{*}=40$ and $t^{*}=100$ to show the width of the resonating band.

Therefore, in the case of thin forest fuel particles, flame puffing effects of the larger fire fronts considered in this study are responsible for $\Delta f / \phi=0.3$. This is $50 \%$ higher than in the thermal thick case when $t_{i g} \sim 10 \mathrm{~s}$. This value is however constant which mean that $\Delta f / \phi=0.3$ even when $t_{i g} \rightarrow \infty$. Hence, the relative uncertainty on $t_{i g}$ is constant but the absolute uncertainty grows as the ignition time increases. In the most general case (which means considering not only the finest fuel elements and considering any fire size), flame puffing frequencies and also any higher frequencies (for instance due to wind/vegetation interactions) are not expected to interact with the kernel and thus will not generate uncertainty on the ignition time calculation. However, lower frequencies due to wind gusts or wind/fire front interactions could be responsible for great uncertainties on the ignition time calculation if theses frequencies are in the range $0.005-0.15 \mathrm{~Hz}$, regardless of the ignition time.

\section{Concluding remarks}

Using the classical ignition theory and a Fourier decomposition for the incoming heat flux on different kind of solid targets, this study quantifies how harmonic fluctuations of the heat flux can affect ignition times regarding a main constant contribution. Hence, for thermally thick target, only slow time-varying fluctuations can affect ignition times due to the characteristic time scale of the associated kernel. Frequencies which have relevant contributions on the ignition time uncertainty are depending linearly on the inverse of the ignition time. However, for a thermally thin target, the characteristic time scale of the kernel allows the later to resonate with the solicitation, showing a higher sensitivity (in comparison with the thermally thick case) to any frequency, plus the existence of particular frequencies (based on the kernel 


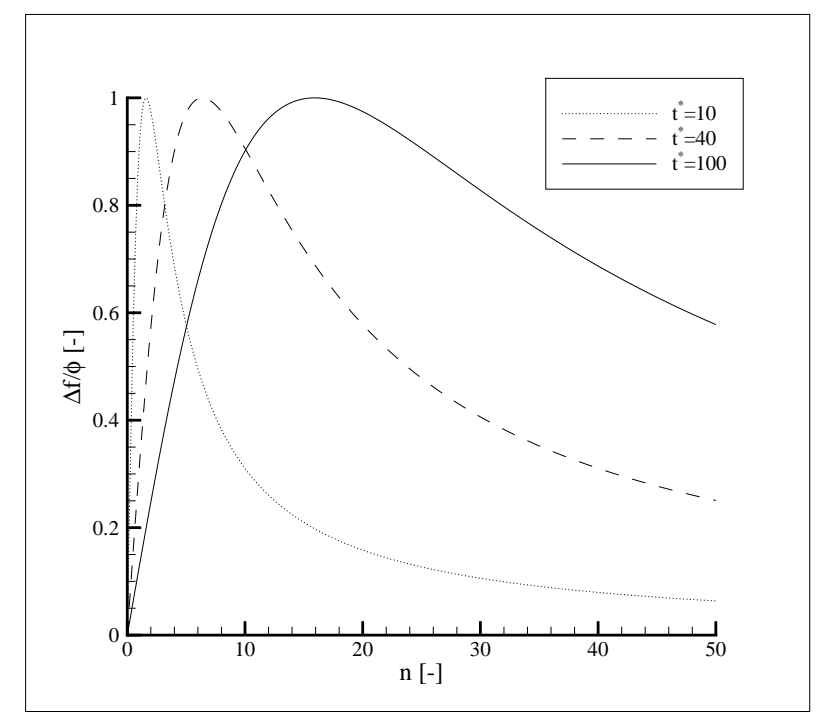

Figure 2. $\Delta f(k, n) / \phi$ for $t^{*}=10, t^{*}=40$ and $t^{*}=100$

characteristic time) which interact actively with the ignition process. These frequencies are depending solely on the kernel characteristic time, contrary to the thermally thick case where it was depending on the ignition time. Hence, thermally thin kernel frequencies can be compared with the characteristic frequency of periodic (or quasi-periodic) physical phenomenon involved in fire propagation such as flame puffing, wind gusts, wind/fire front interactions and wind/vegetation interactions, showing that lowest frequency phenomenon such as wind gusts are the most likely to generate large uncertainties on the ignition time calculation.

\section{References}

[1] C. Fernandez-Pello. in: G. Cox (Ed.), Combustion Fundamentals of Fire. Academic Press, 1995.

[2] J.L. Torero. The SFPE Handbook of Fire Protection Engineering, fourth ed., pages 2.260-2.277. National Fire Protection Association, 2008.

[3] J.G. Quintiere. Fundamentals of Fire Phenomena, pages 171-173. John Wiley, 2006.

[4] P. Reska, P. Borowiec, T. Steinhaus, and J.L. Torero. A methodology for the estimation of ignition delay times in forest fire modelling. Combust. Flame, 159:3652-3657, 2012.

[5] J. Cohen. Relating flame radiation to home ignition using modeling and experimental crown fires. Can. J. Forest Res., 34(8):1616-1626, 2004.

[6] D. Morvan. Physical phenomena and length scales governing the behaviour of wildfires: A case for physical modelling. Fire Tech., 47:437-460, 2011.

[7] G. Atkinson, D. Drysdale, and Y. Wu. Fire driven flow in an inclined trench. Fire Saf. J., pages 141-158, 1995.

[8] J.L. Dupuy, J. Marecha, D. Portier, and J.C. Valette. The effects of slope and fuel bed width on laboratory fire behavior. Int. J. Wildland Fire, 20:272-288, 2011.

[9] M.A. Finney, J. Forthofer, I.C. Grenfell, B.A. Adam, N.K. Akafuah, and K. Saito. A study of flame spread in engineered cardboard fuelbeds; part I: Correlations and observations. In Seventh International Symposium on scale modeling (ISSM-7), 2013, 2013. 
[10] F. Morandini, X. Silvani, L. Rossi, P.-A. Santoni, A. Simeoni, J.-H. Balbi, J.L. Rossi and T. Marcelli. Fire spread experiment across Mediterranean shrub: Influence of wind on flame front properties. Fire Saf. J., 41:229-235, 2006.

[11] R.T. Long, J.L. Torero, J.G. Quintiere, and A.C. Fernandez-Pello. Scale and Transport Considerations on piloted Ignition of PMMA. In Fire Safety Science - Procdeedings of the sixth international symposium, 567-578, 1999.

[12] B. Benkoussas, J.-L. Consalvi, B. Porterie, N. Sardoy, and J.-C. Loraud. Modelling thermal degradation of woody fuel particles. International Journal of Thermal Sciences, 46:319-327, 2007.

[13] H. Carslaw and J. Jaeger. Conduction of heat in Solids, second ed., pages 75-76. Oxford University Press, 1959.

[14] F.W. Mowrer. An analysis of effective thermal properties of thermally thick materials. Fire Saf. J., pages 395-410, 2005.

[15] A. Demharter. Polyurethane rigid foam, a proven thermal insulating material for applications between $+130 \mathrm{C}$ and -196C. Cryogenics, 38:113-117, 1998.

[16] D.D. Drysdale. An Introduction to Fire Dynamics, 2nd ed., page 33. 1999.

[17] V. Tihay. Contribution expérimentale et théorique pour la modélisation de la combustion dans les feux de forêts. PhD thesis, Université de Corse, Pascal Paoli, 2007.

[18] P. Bartoli. Forest fires: improvement of the knowledge of the coupling between flames and vegetative fuels. PhD thesis, Université de Corse, Pascal Paoli ; University of Edinburgh, 2011.

[19] A. Simeoni, J.C. Thomas, P. Bartoli, P. Borowieck, P. Reska, F. Colella, P.A. Santoni, and J.L. Torero. Flammability studies for wildland and wildland-urban interface fires applied to pine needles and solid polymers. Fire Saf. J., 54:203217,2012 .

[20] A.M. Grishin. A Mathematical Modelling of Forest Fires and New Methods of Fighting Them. Publishing House of the Tomsk University, Tomsk, Russia, 1997.

[21] N.P. Cheney, J.S. Gould, and W.R. Catchpole. The influence of fuel, weather and fire shape variables on fire-spread in grasslands. Int. J. Wildland Fire, 3(1):31-44, 1993.

[22] W.R. Catchpole, E.A. Catchpole, B.W. Butler, R.C. Rothermel, G.A. Morris, and D.J. Lathan. Rate of spread of free-burning fires in woody fuels in a wind tunnel. Combust. Sci. and Tech., 131:1-37, 1998.

[23] W.M.G Malalasekera, H.K. Versteeg, and K. Gilchrist. A review of reaserch and an experimental study on the pulsation of buoyant diffusion flames and pool fires. Fire and Materials, 20:261-271, 1996.

[24] P.J. Pagni. Pool fire vortex shedding frequencies, in Applied Mechanics Reviews, 43(8):153-170, 1990.

[25] K. Chetehouna, O. Séro-Guillaume, I. Sochet, and A. Degiovanni. On the experimental determination of flame front positions and of propagation parameters for a fire. Int. J. Heat Mass Trans., 47(9):1148-1157, 2008.

Table 1

\begin{tabular}{ccccc}
\hline Material type & $\lambda\left[\mathrm{W} . \mathrm{m}^{-1} . \mathrm{K}^{-1}\right] \rho\left[\mathrm{kg} . \mathrm{m}^{-3}\right] C p\left[\mathrm{~J} . \mathrm{kg}^{-1} \cdot \mathrm{K}^{-1}\right]$ & $\tau_{K_{H}}[\mathrm{~s}]$ \\
\hline \hline Wood & $0.12-0.17$ & $500-800$ & $1800-2850$ & $270-4000$ \\
\hline Polymer & $0.11-0.6$ & $940-2000$ & $1000-2000$ & $260-10000$ \\
\hline Insulating foam & $0.022-0.037$ & $20-200$ & $1400-2000$ & $2-150$ \\
\hline
\end{tabular}

Physical property ranges from $[14,15,16,17]$ and [18] and thermally thick characteristic time ranges 